\title{
Efficacy of dexamethasone suppression test during the diagnosis of primary pigmented nodular adrenocortical disease in Chinese adrenocorticotropic hormone-independent Cushing syndrome
}

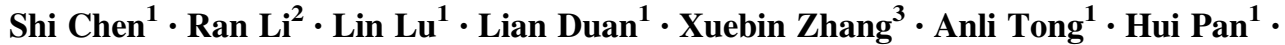 \\ Huijuan Zhu' ${ }^{1}$ Zhaolin Lu ${ }^{1}$
}

Received: 11 June 2017 / Accepted: 20 September 2017 / Published online: 1 November 2017

(C) The Author(s) 2017. This article is an open access publication

\begin{abstract}
Objective To evaluate the cut-off value of the ratio of $24 \mathrm{~h}$ urinary free cortisol ( $24 \mathrm{~h}$ UFC) levels post-dexamethasone to prior-dexamethasone in dexamethasone suppression test (DST) during the diagnosis of primary pigmented nodular adrenocortical disease in Chinese adrenocorticotropic hormone-independent Cushing syndrome.

Design Retrospective study.

Participants The patients diagnosed with primary pigmented nodular adrenocortical disease (PPNAD, $n=25$ ), bilateral macronodular adrenal hyperplasia (BMAH, $n=27)$, and adrenocortical adenoma (ADA, $n=84$ ) were admitted to the Peking Union Medical College Hospital from 2001 to 2016. Estimations Serum cortisol, adrenocorticotropic hormone (ACTH), and $24 \mathrm{~h} \mathrm{UFC} \mathrm{were} \mathrm{measured} \mathrm{before} \mathrm{and} \mathrm{after}$ low-dose dexamethasone suppression test (LDDST) and high-dose dexamethasone suppression test (HDDST).

Results After LDDST and HDDST, $24 \mathrm{~h}$ UFC elevated in patients with PPNAD (paired $t$-test, $P=0.007$ and $P=$ 0.001 ), while it remained unchanged in the BMAH group (paired $t$-test, $P=0.471$ and $P=0.414$ ) and decreased in the
\end{abstract}

Lin Lu

lulin88@sina.com

1 Department of Endocrinology, Peking Union Medical College Hospital, Peking Union Medical College, Chinese Academy of Medical Sciences, Key Laboratory of Endocrinology of National Health and Family Planning Commission, Beijing, China

2 Eight-year Program of Clinical Medicine, Peking Union Medical College Hospital, Peking Union Medical College, Chinese Academy of Medical Sciences, Beijing, China

3 Department of Urology, Peking Union Medical College Hospital, Peking Union Medical College, Chinese Academy of Medical Sciences, Beijing, China
ADA group (paired $t$-test, $P=0.002$ and $P=0.004$ ). The $24 \mathrm{~h}$ UFC level after LDDST was higher in PPNAD and BMAH as compared to ADA $(P<0.017)$, while no significant difference was observed between PPNAD and BMAH. After HDDST, $24 \mathrm{~h}$ UFC was higher in patients with PPNAD as compared to that of ADA and BMAH $(P<$ 0.017). The cut-off value of $24 \mathrm{~h}$ UFC (Post-L-Dex)/(Pre-LDex) was 1.16 with $64.0 \%$ sensitivity and $77.9 \%$ specificity, and the cut-off value of $24 \mathrm{~h}$ UFC (Post-H-Dex)/(Pre-HDex) was 1.08 with $84.0 \%$ sensitivity and $75.6 \%$ specificity. Conclusion The ratio of post-dexamethasone to priordexamethasone had a unique advantage in distinguishing PPNAD from BMAH and ADA.

Keywords Cushing syndrome - Adrenal gland diseases • Carney complex $\cdot$ Primary pigmented nodular adrenocortical disease $\cdot$ Dexamethasone suppression test

\section{Introduction}

Cushing syndrome (CS) is characterized by chronic exposure to excessive glucocorticoid, and thus classified into adrenocorticotropic hormone (ACTH)-dependent and ACTH-independent CS. ACTH-independent CS accounts for approximately $15-20 \%$ of CS, primarily due to the unilateral adrenal tumor such as adrenocortical adenoma (ADA) and adrenal carcinoma that accounts for 10 and 5\%, respectively. The rare causes of ACTH-independent CS include primary bilateral macronodular adrenal hyperplasia (BMAH), primary pigmented nodular adrenal disease (PPNAD), and McCune-Albright syndrome [1].

PPNAD is rarely encountered and accounts for $0.6-1.9 \%$ of CS [2]. It can occur isolated or as a component of the Carney complex (CNC). CNC is a hereditary multiple 
neoplasia syndrome characterized by skin lentigines, myxomas, and endocrine tumors, first described by J. Aidan Carney in 1985 [3]. According to Stratakis et al., 95\% patients with PPNAD fulfilled the diagnostic criteria of CNC [4]; however, other reports on the incidence rate of CNC in patients with PPNAD are limited. The pathological feature of PPNAD constitutes of multiple pigmented cortical nodules and atrophy of the internodular cortex. The typical radiological features of PPNAD may present as multiple nodules of bilateral adrenal glands; however, in most cases, the appearance of adrenal glands with PPNAD might be normal or presented with macronodules [5] that are indistinguishable from BMAH, which is characterized by large adrenal nodules, $>5 \mathrm{~cm}$. Thus, occasionally, the preoperative diagnosis through imaging is misleading and rather challenging $[5,6]$. Therefore, a new method with high sensitivity and specificity that can discriminate PPNAD from other adrenal diseases is an urgent prerequisite.

Several reports have mentioned an anomalous increase in the glucocorticoid level in patients with PPNAD [7-9]. Stratakis et al. reported a paradoxical increase in urinary free cortisol (UFC) in response to dexamethasone during the Liddle test. Moreover, an increase of more than 50\% in $24 \mathrm{~h}$ UFC on day 6 could distinguish PPNAD patients from those with other primary adrenal disorders causing CS with a $69.2 \%$ sensitivity and $80.0 \%$ specificity [4]. Dexamethasone suppression tests (DST) are widely used in the diagnosis of CS. Low-dose dexamethasone suppression test (LDDST) serves as the definitive test in the confirmation of CS, while the high-dose dexamethasone suppression test (HDDST) differentiates between pituitary-dependent and non-pituitarydependent forms of CS. Nevertheless, the usefulness of DST in the diagnosis of PPNAD is yet to be elucidated. In addition, since the level of cortisol differs among races, whether an increase in $>50 \%$ of $24 \mathrm{~h}$ UFC in the Liddle test could also be applied to Asian people is yet to be investigated.

Herein, we analyzed data from 25 patients with PPNAD and control groups consisting of 27 patients with BMAH and 84 with ADA were admitted to the Peking Union Medical College Hospital (PUMCH) from 2001 to 2016. To our knowledge, this was the largest single-center study of PPNAD in Asia. LDDST and HDDST were conducted, and comparisons were made among the three groups. We used the ratio of $24 \mathrm{~h}$ UFC post-dexamethasone to prior-dexamethasone, for the first time, to determine the cut-off value for the evaluation of PPNAD.

\section{Materials and methods}

\section{Patients}

The present study was approved by the Ethics Committee of PUMCH. We retrospectively analyzed the records of 136 patients with ACTH-independent CS who were admitted to PUMCH from 2001 to 2016. All of the patients underwent unilateral epinephrectomy for the preserving of the adrenal gland function. Twenty-five patients were histologically confirmed for PPNAD, 27 patients had BMAH, and 84 were diagnosed with ADA.

\section{Methods}

All the clinical information was extracted from the medical records of PUMCH. The CNC was diagnosed based on the published criteria in 2001 [3]. According to the criteria, the $\mathrm{CNC}$ could be diagnosed if patients fulfilled two major criteria or one major and one supplementary criterion. The screening tests, including echocardiogram, thyroid ultrasonography, breast ultrasonography, pituitary MRI, testicular ultrasonography in males, and transabdominal pelvic ultrasonography in females, were conducted for the confirmation of CNC in all participants. A total of 109 patients received LDDST, and 27 patients were administered $1 \mathrm{mg}$ overnight dexamethasone test. All patients presented abnormal screening test results; moreover, they undertook HDDST immediately after LDDST. LDDST: After 2 days of baseline measurement of $24 \mathrm{~h}$ UFC, dexamethasone was administered orally at the dosage of $0.5 \mathrm{mg}$ every $6 \mathrm{~h}$ for 2 days at 8:00, 14:00, 20:00, and 8:00. The $24 \mathrm{~h}$ UFC was measured on the second day of dexamethasone administration. The ratio of $24 \mathrm{~h}$ UFC postLDDST to before LDDST was denoted as $24 \mathrm{~h}$ UFC (Post-LDex)/(Pre-L-Dex). Similar to LDDST, dexamethasone was administered at the dosage of $2 \mathrm{mg}$ during HDDST. The time point of $24 \mathrm{~h}$ UFC was identical to that of LDDST. The ratio of $24 \mathrm{~h}$ UFC after HDDST to before HDDST was denoted as $24 \mathrm{~h}$ UFC (Post-H-Dex)/(Pre-H-Dex). Serum cortisol, serum $\mathrm{ACTH}$, and $24 \mathrm{~h}$ UFC were measured with the chemiluminescence method using the commercial kits (DPC Biotechnology and Medical Products Cooperation, Tianjin, China). The data of arterial blood pressure, serum sodium and potassium, fasting plasma glucose, plasma glucose after the $75 \mathrm{~g}$ oral glucose tolerance test, and HbAlc levels were collected. Computed tomography (CT) of adrenal glands was performed for each patient, and bone mineral density (BMD) was evaluated using Dual-Energy X-ray absorption assay method to assess the influence of hypercortisolism to bone metabolism.

\section{Statistical analysis}

Statistical analyses were performed using the SPSS statistical package version 22.0. Kolmogorov-Smirnov test was utilized for normal distribution and homogeneity test for a variance. Normal distribution data were expressed as mean \pm standard deviation. Skewed distribution data were expressed as median (P25, P75). Paired $t$-test compared the difference between $24 \mathrm{~h}$ UFC at the basal level and after DST. Chi-square test was used 
to assess the fundamental ratio differences among the groups. Kruskal-Wallis test was used in skewed distribution data to compare the differences among multiple groups of measurement data. The level of significance was corrected in the case of pairwise comparisons and $P$-value $<0.017$ was considered statistically significant. The receiver-operating characteristic (ROC) curve was constructed to assess the usefulness of both LDDST and HDDST in the diagnosis of PPNAD. $24 \mathrm{~h} \mathrm{UFC}$ (Post-L-Dex)/(Pre-L-Dex) and $24 \mathrm{~h}$ UFC (Post-H-Dex)/(Pre-HDex) were employed as test variables independently.

\section{Results}

\section{Baseline characteristics and clinical features of the three groups}

The baseline characteristics are presented in Table 1. A total of 25 patients with PPNAD comprised of 8 males (32\%)

Table 1 Baseline characteristics and clinical presentations of different groups

\begin{tabular}{|c|c|c|c|c|}
\hline & PPNAD & BMAH & $\mathrm{ADA}$ & $P$-value \\
\hline$N$ & 25 & 27 & 84 & \\
\hline Male & $8 \$$ & $13 \#$ & 6 & 0.000 \\
\hline Female & $17 \$$ & $14 \#$ & 78 & 0.000 \\
\hline $\begin{array}{l}\text { Age of diagnosis } \\
\text { (years) }\end{array}$ & $23 \pm 11$ & $50 \pm 10$ & $34 \pm 9$ & 0.58 \\
\hline Hypertension & $\begin{array}{l}19 \text { of } 25 \\
(76.0 \%)^{*}\end{array}$ & $\begin{array}{l}27 \text { of } 27 \\
(100 \%) \#\end{array}$ & $\begin{array}{l}49 \text { of } 61 \\
(80.3 \%)\end{array}$ & 0.03 \\
\hline $\begin{array}{l}\text { Osteoporosis or } \\
\text { osteopenia }\end{array}$ & $\begin{array}{l}18 \text { of } 23 \\
(78.3 \%)\end{array}$ & $\begin{array}{l}20 \text { of } 27 \\
(74.1 \%)\end{array}$ & $\begin{array}{l}24 \text { of } 50 \\
(48.0 \%) \$\end{array}$ & 0.015 \\
\hline Hypokalemia & $\begin{array}{l}3 \text { of } 25 \\
(12.0 \%)^{*}\end{array}$ & $\begin{array}{l}14 \text { of } 27 \\
(51.9 \%)\end{array}$ & $\begin{array}{l}28 \text { of } 84 \\
(33.3 \%)\end{array}$ & 0.009 \\
\hline IGT or DM & $\begin{array}{l}14 \text { of } 25 \\
(56.0 \%)\end{array}$ & $\begin{array}{l}18 \text { of } 27 \\
(66.7 \%)\end{array}$ & $\begin{array}{l}39 \text { of } 80 \\
(48.8 \%)\end{array}$ & 0.263 \\
\hline
\end{tabular}

$P P N A D$ primary pigmented nodular adrenocortical disease, $B M A H$ bilateral macronodular adrenal hyperplasia, $A D A$ adrenocortical adenoma, IGT impaired glucose tolerance, $D M$ diabetes mellitus

* PPNAD vs. BMAH, $P<0.017$; \# BMAH vs. ADA, $P<0.017$; $\$$ PPNAD vs. ADA $P<0.017$

Table 2 Levels of $24 \mathrm{~h} \mathrm{UFC}$ before and after dexamethasone and 17 females (68\%). The BMAH group consisted of 14 females (51.9\%) while the ADA group comprised of $92.9 \%$ females (78/84), suggesting that the female constituent ratio was higher in the ADA group as compared to the other two groups $(P$-value $<0.017)$. The mean age of the patients with PPNAD, BMAH, and ADA was $23 \pm 11,50 \pm 10$, and 34 \pm 9 years, respectively. Although no significant difference was observed between the groups, patients with PPNAD seemed to have an earlier onset age.

As shown in Table 1, a majority of the patients exhibited typical CS manifestations such as hypertension, weight gain, and abnormal glucose metabolism, and decreased BMD. In the present study, patients in the PPNAD group seemed to have a higher incidence rate of developing decreased BMD (osteopenia or osteoporosis) than those with ADA (78.3 vs. $48.0 \%, P<0.017)$, while no differences were found between PPNAD and BMAH groups. In addition, patients with PPNAD had a lower incidence rate of hypokalemia as compared to BMAH (12.0 vs. $51.9 \%, P$ $<0.017$ ). In the BMAH group, all the 27 patients developed hypertension, indicating a significant difference between BMAH and other groups (100 vs. 76.0\%, $P<0.017 ; 100$ vs. $80.3 \%, P<0.017$ ). With respect to glucose metabolism, no statistically significant differences were observed among the three groups $(P=0.263)$.

\section{Laboratory examinations of the three groups}

In all participants, the serum ACTH levels were $<10 \mathrm{pg} / \mathrm{mL}$, providing support for the diagnosis of ACTH-independent CS accordingly. Table 2 displayed the $24 \mathrm{~h}$ UFC levels before and after administration of dexamethasone. The baseline of $24 \mathrm{~h}$ UFC in patients with PPNAD was higher than that of the patients with ADA (383.50 vs. 224.42, normal range: $12.3-103.5 \mu \mathrm{g} / 24 \mathrm{~h}, P<0.017$, Fig. 1a). No statistical difference was observed between the other groups. In the ADA group, the majority of the patients showed an increased UFC level, while $9.4 \%$ of the patients exhibited a $24 \mathrm{~h}$ UFC level within the normal range. After LDDST and HDDST, the $24 \mathrm{~h}$ UFC elevated in patients

\begin{tabular}{lllll}
\hline Group & PPNAD & BMAH & ADA & $P$-value \\
\hline Baseline $(\mu \mathrm{g} / \mathrm{d})$ & $383.50(271.61,452.97) \#$ & $314.70(151.04,557.16)$ & $224.42(144.50,334.88)$ & 0.002 \\
LDDST $(\mu \mathrm{g} / \mathrm{d})$ & $497.35(389.86,717.70) \#$ & $325.60(124.28,557.03)$ & $181.66(108.00,252.00) \$$ & 0.000 \\
HDDST $(\mu \mathrm{g} / \mathrm{d})$ & $495.30(402.97,876.55) \#$ & $339.84(175.42,526.13) *$ & $184.50(116.20,309.61)$ & 0.000 \\
Post/Pre $(\mathrm{L})$ & $1.29(0.91,1.71) \#$ & $0.93(0.82,1.23)$ & $0.78(0.51,1.07)$ & 0.000 \\
Post/Pre $(\mathrm{H})$ & $1.48(1.14,2.09) \#$ & $0.94(0.76,1.59) *$ & $0.92(0.71,1.07)$ & 0.000
\end{tabular}

$P P N A D$ pigmented nodular adrenocortical disease, $B M A H$ bilateral macronodular adrenal hyperplasia, $A D A$ adrenocortical adenoma, $L D D S T$ low-dose dexamethasone suppression test, HDDST high-dose dexamethasone suppression test, Post/Pre (L) the ratio of $24 \mathrm{~h}$ UFC posterior to LDDST and prior to LDDST, Post/Pre $(H)$ the ratio of $24 \mathrm{~h}$ UFC posterior to HDDST and prior to HDDST

* PPNAD vs. BMAH, $P<0.017$; \# PPNAD vs. ADA, $P<0.017$; $\$$ BMAH vs. ADA, $P<0.017$ 

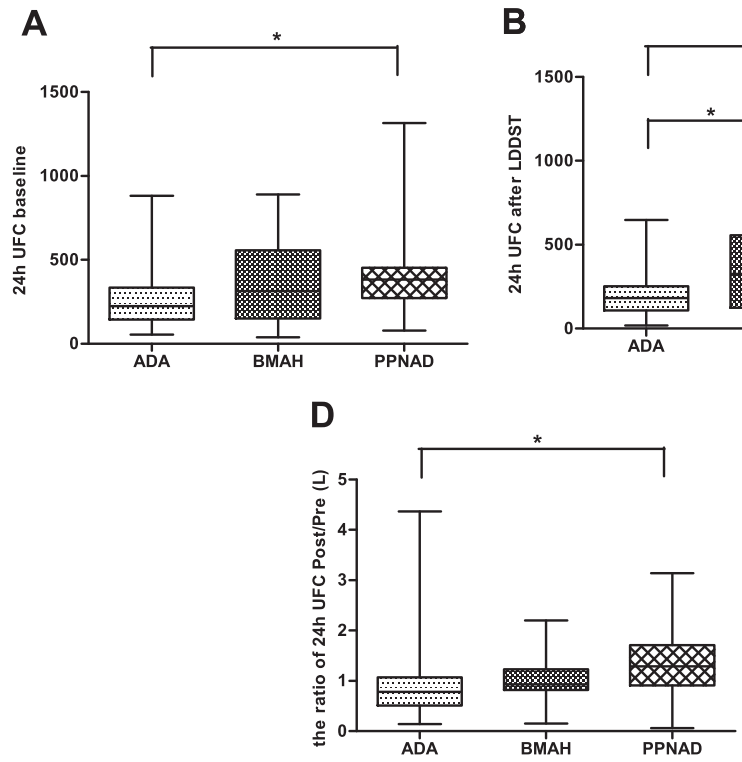

B

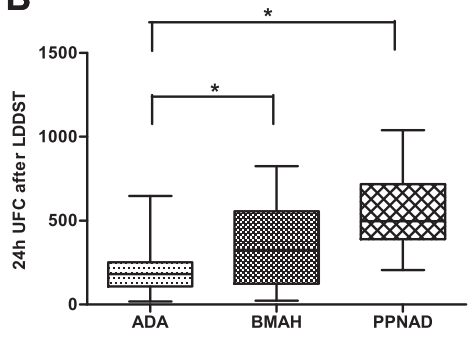

C

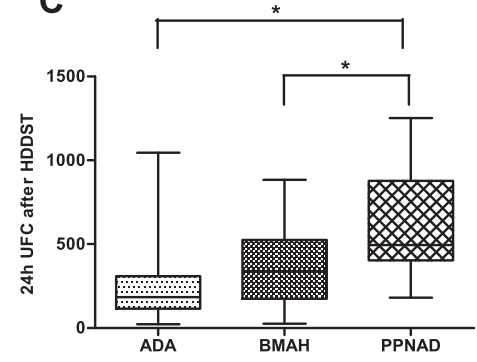

E

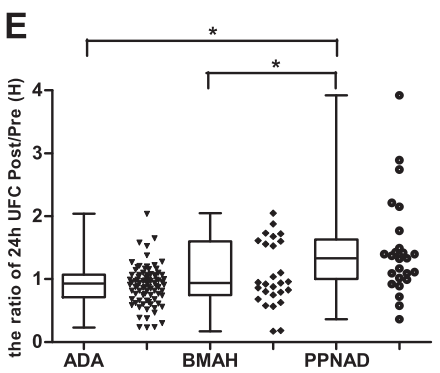

Fig. $124 \mathrm{~h}$ UFC levels before and after administration of dexamethasone. The basal level of $24 \mathrm{~h}$ UFC in the PPNAD group was higher than that of ADA (Fig. 1a, $P<0.017$ ), after low-dose and highdose dexamethasone. $24 \mathrm{~h}$ UFC in patients with PPNAD increased, while in patients with ADA and BMAH the $24 \mathrm{~h}$ UFC decreased or remained unaltered. The $24 \mathrm{~h}$ UFC level after LDDST was higher in the PPNAD group and BMAH as compared to ADA $(P<0.017)$, while no significant difference between PPNAD and BMAH was observed (Fig. 1b). After administration of HDDST, $24 \mathrm{~h}$ UFC was higher in patients with PPNAD as compared to that of ADA and BMAH (Fig. 1c, $P<0.017$ ). The ratio of $24 \mathrm{~h}$ UFC posterior to DST to before DST (Fig. 1d, e) showed a significant difference between PPNAD and the other two groups

Table 3 Clinical manifestations of the patients with CNC

\begin{tabular}{lllll}
\hline Number & Gender & Age (years) & PPNAD & Other manifestations of CNC \\
\hline 1 & M & 14 & Yes & Spotty hyperpigmentation in lower eyelid and lips \\
2 & F & 23 & Yes & Spotty hyperpigmentation in face and bulbar conjunctiva \\
3 & F & 17 & Yes & Spotty hyperpigmentation in face and hands, with similar family history \\
4 & F & 28 & Yes & Spotty hyperpigmentation in lips and buccal mucosa, pancreatic cyst, nodule in unilateral breast \\
5 & F & 19 & Yes & Spotty hyperpigmentation in face and lips, solid nodules in bilateral breast \\
6 & F & 14 & Yes & Multiple hypoechoic nodules of the thyroid gland \\
7 & M & 19 & Yes & Spotty hyperpigmentation in face, cyst in the head of epididymis \\
8 & F & 25 & Yes & Spotty hyperpigmentation in lips and buccal mucosa, hypoechoic nodules in thyroid gland and breast, \\
& & & & skeletal lesions \\
9 & F & 17 & Yes & Spotty hyperpigmentation in lips and buccal mucosa, hypoechoic nodules in thyroid gland and breast
\end{tabular}

PPNAD pigmented nodular adrenocortical disease

with PPNAD (paired $t$-test, $P=0.007$ and $P=0.001$ ); among these, 12 patients $(48 \%)$ presented an elevation of $24 \mathrm{~h}$ UFC $>50 \%$ after HDDST. On the other hand, $24 \mathrm{~h}$ UFC remained unaltered in the BMAH group (paired $t$-test, $P=0.471$ and $P=0.414$ ) and decreased in the ADA group (paired $t$-test, $P=0.002$ and $P=0.004$, Fig. 1b, c). The 24 $h$ UFC level after LDDST was higher in the PPNAD and BMAH groups as compared to ADA $(P<0.017)$, while no significant difference was observed between PPNAD and BMAH. After administration of HDDST, $24 \mathrm{~h}$ UFC was higher in patients with PPNAD as compared to that of ADA and BMAH $(P<0.017)$.
In order to clarify the level of $24 \mathrm{~h}$ UFC variation, the ratio of $24 \mathrm{~h}$ UFC post-DST to $24 \mathrm{~h}$ UFC pre-DST was calculated and denoted as $24 \mathrm{~h}$ UFC (Post-L-Dex)/(Pre-LDex) and $24 \mathrm{~h}$ UFC (Post-H-Dex)/(Pre-H-Dex) after LDDST and HDDST, respectively. The ratio $>1$ suggested that $24 \mathrm{~h}$ UFC elevated after DST. Furthermore, after LDDST, the 24 $\mathrm{h}$ UFC (Post-L-Dex)/(Pre-L-Dex) in the PPNAD group was significantly higher than that of the ADA group (1.29 vs. $0.78, P<0.017)$, whereas the ratio between PPNAD and BMAH showed no difference (Fig. 1d). After administration of high-dose dexamethasone, $24 \mathrm{~h}$ UFC (Post-H-Dex)/(PreH-Dex) in PPNAD, BMAH, and ADA was 1.48 (1.14, 
Table 4 Clinical features and laboratory examinations of patients with isolated PPNAD and patients with CNC

\begin{tabular}{|c|c|c|c|}
\hline & Isolated PPNAD & Carney syndrome & $P$-value \\
\hline Age (years) & $22.13 \pm 9.91$ & $19.56 \pm 4.57$ & 0.318 \\
\hline Number & 16 & 9 & 0.667 \\
\hline Female & 10 & 7 & \\
\hline Male & 6 & 2 & \\
\hline BMI $\left(\mathrm{kg} / \mathrm{m}^{2}\right)$ & 24.85 & 26.63 & 0.327 \\
\hline Hypertension & 11 & 8 & 0.380 \\
\hline Grade I & 3 & 2 & \\
\hline Grade II & 2 & 3 & \\
\hline Grade III & 6 & 3 & \\
\hline IGT or DM & 9 & 5 & 1.000 \\
\hline IGT & 8 & 4 & \\
\hline $\mathrm{DM}$ & 1 & 1 & \\
\hline TC (mmol/L) & 6.01 & 5.25 & 0.213 \\
\hline TG (mmol/L) & 1.81 & 1.46 & 0.491 \\
\hline LDL-C (mmol/L) & 3.81 & 3.03 & 0.122 \\
\hline HDL-C (mmol/L) & 1.65 & 1.61 & 0.869 \\
\hline Potassium (mmol/L) & 4.00 & 3.96 & 0.873 \\
\hline $\begin{array}{l}\text { Osteopenia or } \\
\text { osteoporosis }\end{array}$ & 12 & 6 & 1.000 \\
\hline Osteopenia & 3 & 1 & \\
\hline Osteoporosis & 9 & 5 & \\
\hline $\begin{array}{c}\text { Severe } \\
\text { osteoporosis }\end{array}$ & 2 & 1 & \\
\hline Fatty liver & 5 & 3 & 1.000 \\
\hline \multirow[t]{3}{*}{ Adrenal gland CT } & $\begin{array}{l}4 \text { with normal } \\
\text { adrenal glands }\end{array}$ & $\begin{array}{l}2 \text { with normal } \\
\text { adrenal glands }\end{array}$ & \\
\hline & $\begin{array}{l}5 \text { with unilateral } \\
\text { nodules }\end{array}$ & $\begin{array}{l}1 \text { with unilateral } \\
\text { nodules }\end{array}$ & \\
\hline & $\begin{array}{l}8 \text { with bilateral } \\
\text { nodules }\end{array}$ & $\begin{array}{l}6 \text { with bilateral } \\
\text { nodules }\end{array}$ & \\
\hline \multicolumn{4}{|l|}{$24 \mathrm{~h} \mathrm{UFC}$} \\
\hline Baseline & $\begin{array}{l}375.05(282.18 \\
411.40)\end{array}$ & $\begin{array}{l}423.10(216.88, \\
622.96)\end{array}$ & 0.301 \\
\hline LDDST & $\begin{array}{l}482.20(344.96 \\
770.60)\end{array}$ & $\begin{array}{l}556.92(389.86, \\
778.85)\end{array}$ & 0.558 \\
\hline HDDST & $\begin{array}{l}485.42(339.17 \\
745.01)\end{array}$ & $\begin{array}{l}862.90(391.21, \\
948.76)\end{array}$ & 0.229 \\
\hline Post/Pre (L) & $1.31(1.04,1,75)$ & $1.50(0.79,2.15)$ & 0.978 \\
\hline Post/Pre (H) & $1.49(1.12,2.08)$ & $1.59(1.05,2.18)$ & 0.846 \\
\hline
\end{tabular}

PPNAD pigmented nodular adrenocortical disease, BMI body mass index, $I G T$ impaired glucose tolerance, $D M$ diabetes mellitus, $T C$ total cholesterol, $T G$ triglyceride, $L D L-C$ low-density lipoprotein cholesterol, $H D L-C$ high-density lipoprotein cholesterol, $24 \mathrm{~h} \mathrm{UFC} 24 \mathrm{~h}$ urinary free cortisol, Post/Pre $(L)$ the ratio of $24 \mathrm{~h}$ UFC posterior to LDDST and prior to LDDST, Post/Pre $(H)$ the ratio of $24 \mathrm{~h}$ UFC posterior to HDDST and prior to HDDS

2.09), $0.94(0.76,1.59)$, and $0.92(0.71,1.07)$, respectively, and the ratio in the PPNAD group was distinctively higher than that of BMAH and ADA $(P<0.017$, Fig. 1e).
Clinical features and laboratory examinations between isolated PPNAD and CNC

In 9/25 patients (36.0\%), PPNAD occurred as a component of CNC; the clinical features were summarized in Table 3. The cohort comprised of two males and seven females, with an average age of 19.6 (range, 14-28) years. Spotty hyperpigmentation was the most frequent manifestation and could be observed in all the patients. In addition to spotty hyperpigmentation, a 19-year-old male also demonstrated a cyst in the head of the epididymis. Multiple solid hypoechoic nodules of the thyroid gland were found in three females, whereas two had nodules in the breast. Two females had solid nodules in the unilateral or bilateral breast. No cardiac myxoma and tumors of other endocrine glands were found in patients with CNC. Furthermore, comparisons between patients with isolated PPNAD and patients with CNC (Table 4) did not reveal any significant differences in the clinical features such as age, sex, constituent ratio, body mass index (BMI), the incidence rate of hypertension, disturbance of carbohydrate metabolism, dyslipidemia, and decreased BMD. The $24 \mathrm{~h}$ UFC levels before and after DST did not show any difference between the patients with isolated PPNAD and those with $\mathrm{CNC}(P>$ $0.05)$.

\section{ROC and cut-off values in the diagnosis of PPNAD}

$24 \mathrm{~h}$ UFC (Post-L-Dex)/(Pre-L-Dex) and $24 \mathrm{~h}$ UFC (PostH-Dex)/(Pre-H-Dex) were used as the test variables. The ROC curve was constructed with PPNAD that was served as the state variable, and its value was 1 . Taking the leftmost point of the curve as the cut-off point, the area under the ROC curve (AUC) was 0.733 after LDDST, and the cutoff value of $24 \mathrm{~h}$ UFC (Post-L-Dex)/(Pre-L-Dex) was 1.16 with $64.0 \%$ sensitivity and $77.9 \%$ specificity. Similarly, the AUC was 0.802 after HDDST, and the cut-off value of $24 \mathrm{~h}$ UFC (Post-H-Dex)/(Pre-H-Dex) was 1.08 with $84.0 \%$ sensitivity and $75.6 \%$ specificity (Fig. 2).

\section{Discussion}

PPNAD occurs as a rare cause of CS, accounting for $0.6-1.9 \%$ of all such patients [2]. CNC is an autosomal dominant inherited and multiple neoplasia syndrome characterized by skin tumors and pigmented lesions, cardiac myxomas, schwannomas, breast adenomas, bone lesions and various endocrine disorders caused by tumors of the pituitary and thyroid glands, pancreas, and/or gonads [10, 11]. A total of $26-60 \%$ of the $\mathrm{CNC}$ patients exhibited PPNAD, and it is the most common endocrine tumor associated with $\mathrm{CNC}[3,10,12]$. In our study, $36.0 \%$ 


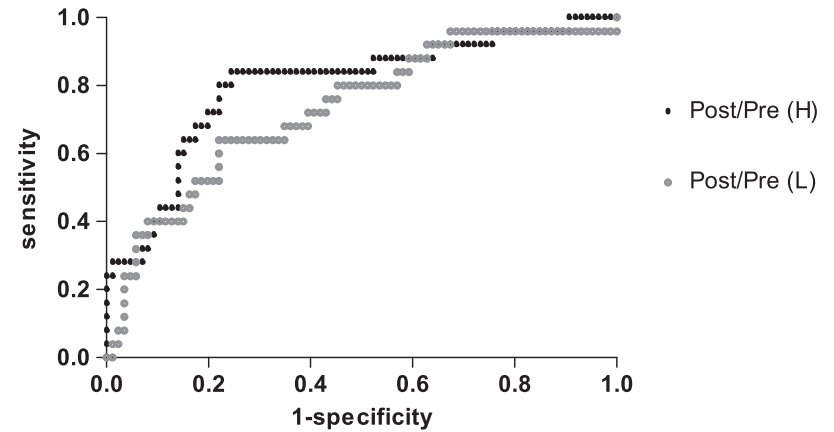

Fig. 2 ROC curve was constructed with the ratio of $24 \mathrm{~h}$ UFC Post/Pre (L) and Post/Pre $(\mathrm{H})$ as the detection variable. The AUC was 0.733 and 0.802 after low-dose and high-dose dexamethasone, respectively

PPNAD patients had the components of CNC, and all of them presented spotty pigmentation in the skin or the mucosa, five females demonstrated the hypoechoic nodules of the thyroid gland and/or breast, and a male developed a cyst in the head of the epididymis. Nevertheless, the commonly reported manifestation, cardiac myxoma [13], was not found in our patients. Stratakis et al. reported that 20/21 patients (95\%) showed PPNAD that occurred as a component of CNC [4]. Such an enormous difference in the incidence rate of CNC in patients with PPNAD between the current study (36\%) and that by Stratakis et al. (95\%) might be attributed to the ethnic differences. Additionally, the sample size of both studies was not sufficiently large, which leads to inevitable bias to the results. Further investigations with expanded sample size need to be undertaken in order to clarify the genetic distinctions among various races.

DST is commonly used in the diagnosis and differential diagnosis of ACTH-dependent CS. LDDST or $1 \mathrm{mg}$ overnight DST is used for screening the presence of CS in the patient, while HDDST is used to distinguish CS from other ACTH-dependent CS; $>50 \%$ suppression of cortisol concentration indicates CS. However, limited studies are available concerning the administration of dexamethasone in ACTH-independent CS since the baseline of serum ACTH level is relatively low. Several reports have mentioned a paradoxical increase in the glucocorticoid level after administration of dexamethasone in patients with PPNAD [14-17]. Silverman et al. reported a patient with CS secondary to bilateral nodular adrenocortical hyperplasia, in whom urinary $17-\mathrm{OHCS}$ could not be suppressed by a large dose of dexamethasone, and the adrenal pathology demonstrated cortical hyperplasia with multiple small nodules [14]. In 1999 Stratakis et al. found that UFC levels on day 6 of the Liddle test had the highest accuracy in the diagnosis of PPNAD, and an increase of $>50 \%$ UFC levels could discriminate $9 / 13$ patients with PPNAD from other primary adrenocortical disorders [4]. In the current study, we also found that after DST, the $24 \mathrm{~h}$ UFC levels in patients with PPNAD increased, while in the other two groups the $24 \mathrm{~h}$ UFC levels remained unchanged or even decreased, which suggested the usefulness of DST in the diagnosis of PPNAD. In patients with ADA, the $24 \mathrm{~h} \mathrm{UFC}$ levels were slightly decreased after DST, which might be partially attributed to the suppressibility of those patients whose basal $24 \mathrm{~h}$ UFC values were within the normal range.

Herein, we used the ratio of $24 \mathrm{~h}$ UFC postdexamethasone to prior-dexamethasone, for the first time, in the diagnosis of PPNAD. After LDDST, the ratio of $24 \mathrm{~h}$ UFC Post/Pre (L) in the PPNAD group was significantly higher than that in the ADA group, while it could not differentiate PPNAD from BMAH. After administration of high-dose dexamethasone, a statistically significant difference between PPNAD and BMAH was noted, indicating the diagnostic value of DST, especially the HDDST could identify PPNAD from both BMAH and ADA. Our study revealed the ratio of $24 \mathrm{~h}$ UFC after LDDST to the baseline value $>1.16$ with $64.0 \%$ sensitivity and $77.9 \%$ specificity. Similarly, when the value of $24 \mathrm{~h}$ UFC (Post-H-Dex)/UFC (Pre-H-Dex) is $>1.08$, the sensitivity and specificity increased to 84.0 and $75.6 \%$, respectively. Compared to the previous study using $24 \mathrm{~h}$ UFC of $>50 \%$ increase on day 6 of the Liddle test, the degree of UFC level was slightly lower in our study. This phenomenon might be attributed to the theory that the proportion of patients with isolated PPNAD was different between our study and that by Stratakis et al. The molecular mechanism underlying the paradoxical response to dexamethasone in patients with PPNAD was due to an increased expression of glucocorticoid receptor in PPNAD nodules [17]. The CNC is primarily caused by germline mutations in the protein kinase A regulatory subunit 1A (PRKAR1A) gene [18-22]. Nevertheless, several studies demonstrated that patients with isolated PPNAD exhibited specific molecular genetic abnormalities with mutations in phosphodiesterase PDE11A, PDE8B, and the PKA catalytic subunit PRKACA gene [23-25]. The mutations in various gene loci may differentially influence the cAMP/PKA pathway in patients with isolated PPNAD and $\mathrm{CNC}$, leading to variable levels of UFC.

Nevertheless, the present study exhibited some limitations. Since we mainly focused on the clinical study regarding the usefulness of DST in the diagnosis of PPNAD, the genetic mutations were not assessed in the participants, which made it impossible to compare the genetic abnormities between patients with isolated PPNAD and those with CNC. Furthermore, due to the retrospective nature of the current study, some clinical data were missing, which could lead to a potential bias in our study.

In conclusion, DST, especially HDDST, is greatly beneficial in the early diagnosis of PPNAD. When the radiological examination could not provide valuable information, DST could detect the patients with subclinical, 
atypical PPNAD-associated manifestations and distinguish PPNAD from other adrenal diseases. With respect to the Chinese population, the cut-off value of $24 \mathrm{~h}$ UFC (Post-HDex)/(Pre-H-Dex) was 1.08 with $84.0 \%$ sensitivity and $7.6 \%$ specificity. However, the cut-off values of $24 \mathrm{~h}$ UFC levels between different races need to be investigated further.

Acknowledgements We thank Yimin Qu for the valuable suggestions for statistical analysis.

\section{Compliance with ethical standards}

Conflict of interest The authors declare that they have no competing interests.

Open Access This article is distributed under the terms of the Creative Commons Attribution 4.0 International License (http://crea tivecommons.org/licenses/by/4.0/), which permits unrestricted use, distribution, and reproduction in any medium, provided you give appropriate credit to the original author(s) and the source, provide a link to the Creative Commons license, and indicate if changes were made.

\section{References}

1. A. Lacroix, R.A. Feelders, C.A. Stratakis, L.K. Nieman, Cushing's syndrome. Lancet 386(9996), 913-927 (2015). https://doi.org/10. 1016/S0140-6736(14)61375-1

2. W.F. Young, J.A. Carney, B.U. Musa, N.M. Wulffraat, J.W. Lens, H.A. Drexhage, Familial Cushing's syndrome due to primary pigmented nodular adrenocortical disease. Reinvestigation 50 years later. N. Engl. J. Med. 321(24), 1659-1664 (1989). https:// doi.org/10.1056/nejm198912143212407

3. C.A. Stratakis, L.S. Kirschner, J.A. Carney, Clinical and molecular features of the Carney complex: diagnostic criteria and recommendations for patient evaluation. J. Clin. Endocrinol. Metab. 86(9), 4041-4046 (2001). https://doi.org/10.1210/jcem.86. 9.7903

4. C.A. Stratakis, N. Sarlis, L.S. Kirschner, J.A. Carney, J.L. Doppman, L.K. Nieman, G.P. Chrousos, D.A. Papanicolaou, Paradoxical response to dexamethasone in the diagnosis of primary pigmented nodular adrenocortical disease. Ann. Intern. Med. 131(8), 585-591 (1999)

5. D. Vezzosi, F. Tenenbaum, L. Cazabat, F. Tissier, M. Bienvenu, C.A. Carrasco, M. Laloi-Michelin, G. Barrande, H. Lefebvre, S. Hieronimus, A. Tabarin, X. Bertagna, P. Legmann, M.C. Vantyghem, J. Bertherat, Hormonal, radiological, NP-59 scintigraphy, and pathological correlations in patients with Cushing's syndrome due to primary pigmented nodular adrenocortical disease (PPNAD). J. Clin. Endocrinol. Metab. 100(11), 4332-4338 (2015). https://doi.org/10.1210/jc.2015-2174

6. K.S. Jhaveri, F. Wong, S. Ghai, M.A. Haider, Comparison of CT histogram analysis and chemical shift MRI in the characterization of indeterminate adrenal nodules. Am. J. Roentgenol. 187(5), 1303-1308 (2006). https://doi.org/10.2214/Ajr.05.1022

7. H.J. Ruder, D.L. Loriaux, M.B. Lipsett, Severe osteopenia in young-adults associated with Cushings-syndrome due to micronodular adrenal disease. J. Clin. Endocr. Metab. 39(6), 1138-1147 (1974)
8. M.A. Zeiger, L.K. Nieman, G.B. Cutler, G.P. Chrousos, J.L. Doppman, W.D. Travis, J.A. Norton, Primary bilateral adrenocortical causes of Cushings-syndrome. Surgery 110(6), 1106-1115 (1991)

9. W. Oelkers, V. Bahr, J. Hensen, H. Pickartz, Primary adrenocortical micronodular adenomatosis causing Cushing's-syndrome - effects of ketoconazole on steroid-production and invitro performance of adrenal-cells. Acta Endocrinol-Cop 113(3), 370-377 (1986)

10. M.Q. Almeida, C.A. Stratakis, Carney complex and other conditions associated with micronodular adrenal hyperplasias. Best Pract. Res. Clin. Endocrinol. Metab. 24(6), 907-914 (2010). https://doi.org/10.1016/j.beem.2010.10.006

11. R. Correa, P. Salpea, C.A. Stratakis, Carney complex: an update. Eur. J. Endocrinol. 173(4), M85-M97 (2015). https://doi.org/10. 1530/EJE-15-0209

12. J. Bertherat, A. Horvath, L. Groussin, S. Grabar, S. Boikos, L. Cazabat, R. Libe, F. Rene-Corail, S. Stergiopoulos, I. Bourdeau, T. Bei, E. Clauser, A. Calender, L.S. Kirschner, X. Bertagna, J.A. Carney, C.A. Stratakis, Mutations in regulatory subunit type 1A of cyclic adenosine 5'-monophosphate-dependent protein kinase (PRKAR1A): phenotype analysis in 353 patients and 80 different genotypes. J. Clin. Endocrinol. Metab. 94(6), 2085-2091 (2009). https://doi.org/10.1210/jc.2008-2333

13. C.A. Stratakis, J.A. Carney, J.P. Lin, D.A. Papanicolaou, M. Karl, D.L. Kastner, E. Pras, G.P. Chrousos, Carney complex, a familial multiple neoplasia and lentiginosis syndrome. Analysis of 11 kindreds and linkage to the short arm of chromosome 2. J. Clin. Invest. 97(3), 699-705 (1996). https://doi.org/10.1172/JCI118467

14. S.R. Silverman, R.T. Marnell, L.J. Sholiton, E.E. Werk, Failure of dexamethasone suppression test to indicate bilateral adrenocortical hyperplasia in Cushing's syndrome. J. Clin. Endocrinol. Metab. 23, 167-172 (1963). https://doi.org/10.1210/jcem-23-2-167

15. P. Demoor, H. Roels, K. Delaere, J. Crabbe, Unusual case of adrenocortical hyperfunction. J. Clin. Endocrinol. Metab. 25, 612-620 (1965). https://doi.org/10.1210/jcem-25-5-612

16. R.V. Brooks, S.L. Jeffcoate, D.R. London, F.T. Prunty, P.M. Smith, Intermittent Cushing's syndrome with anomalous response to dexamethasone. J. Endocrinol. 36(1), 53-61 (1966)

17. I. Bourdeau, A. Lacroix, W. Schurch, P. Caron, T. Antakly, C.A. Stratakis, Primary pigmented nodular adrenocortical disease: paradoxical responses of cortisol secretion to dexamethasone occur in vitro and are associated with increased expression of the glucocorticoid receptor. J. Clin. Endocrinol. Metab. 88(8), 3931-3937 (2003). https://doi.org/10.1210/jc.2002-022001

18. J. Bertherat, L. Groussin, F. Sandrini, L. Matyakhina, T. Bei, S. Stergiopoulos, T. Papageorgiou, I. Bourdeau, L.S. Kirschner, C. Vincent-Dejean, K. Perlemoine, C. Gicquel, X. Bertagna, C.A. Stratakis, Molecular and functional analysis of PRKAR1A and its locus (17q22-24) in sporadic adrenocortical tumors: 17q losses, somatic mutations, and protein kinase A expression and activity. Cancer Res. 63(17), 5308-5319 (2003)

19. L.S. Kirschner, J.A. Carney, S.D. Pack, S.E. Taymans, C. Giatzakis, Y.S. Cho, Y.S. Cho-Chung, C.A. Stratakis, Mutations of the gene encoding the protein kinase A type I-alpha regulatory subunit in patients with the Carney complex. Nat. Genet. 26(1), 89-92 (2000). https://doi.org/10.1038/79238

20. L.S. Kirschner, F. Sandrini, J. Monbo, J.P. Lin, J.A. Carney, C.A. Stratakis, Genetic heterogeneity and spectrum of mutations of the PRKAR1A gene in patients with the Carney complex. Hum. Mol. Genet. 9(20), 3037-3046 (2000)

21. L. Groussin, E. Jullian, K. Perlemoine, A. Louvel, B. Leheup, J.P. Luton, X. Bertagna, J. Bertherat, Mutations of the PRKAR1A gene in Cushing's syndrome due to sporadic primary pigmented nodular adrenocortical disease. J. Clin. Endocrinol. Metab. 87(9), 4324-4329 (2002). https://doi.org/10.1210/jc.2002-020592 
22. R. Mineo, S. Tamba, Y. Yamada, T. Okita, Y. Kawachi, R. Mori, M. Kyo, K. Saisho, Y. Kuroda, K. Yamamoto, A. Furuya, T. Mukai, T. Maekawa, Y. Nakamura, H. Sasano, Y. Matsuzawa, A. Novel, Mutation in the type Ialpha regulatory subunit of protein kinase A (PRKAR1A) in a Cushing's syndrome patient with primary pigmented nodular adrenocortical disease. Intern. Med. 55 (17), 2433-2438 (2016). https://doi.org/10.2169/internalmedicine. 55.6605

23. A. Horvath, S. Boikos, C. Giatzakis, A. Robinson-White, L. Groussin, K.J. Griffin, E. Stein, E. Levine, G. Delimpasi, H.P. Hsiao, M. Keil, S. Heyerdahl, L. Matyakhina, R. Libe, A. Fratticci, L.S. Kirschner, K. Cramer, R.C. Gaillard, X. Bertagna, J.A. Carney, J. Bertherat, I. Bossis, C.A. Stratakis, A genome-wide scan identifies mutations in the gene encoding phosphodiesterase 11A4 (PDE11A) in individuals with adrenocortical hyperplasia.
Nat. Genet. 38(7), 794-800 (2006). https://doi.org/10.1038/ ng1809

24. A. Horvath, V. Mericq, C.A. Stratakis, Mutation in PDE8B, a cyclic AMP-specific phosphodiesterase in adrenal hyperplasia. N. Engl. J. Med. 358(7), 750-752 (2008). https://doi.org/10.1056/ NEJMc0706182

25. F. Beuschlein, M. Fassnacht, G. Assie, D. Calebiro, C.A. Stratakis, A. Osswald, C.L. Ronchi, T. Wieland, S. Sbiera, F.R. Faucz, K. Schaak, A. Schmittfull, T. Schwarzmayr, O. Barreau, D. Vezzosi, M. Rizk-Rabin, U. Zabel, E. Szarek, P. Salpea, A. Forlino, A. Vetro, O. Zuffardi, C. Kisker, S. Diener, T. Meitinger, M. J. Lohse, M. Reincke, J. Bertherat, T.M. Strom, B. Allolio, Constitutive activation of PKA catalytic subunit in adrenal Cushing's syndrome. N. Engl. J. Med. 370(11), 1019-1028 (2014). https://doi.org/10.1056/NEJMoa1310359 